\title{
A APRENDIZAGEM SIGNIFICATIVA DE AUSUBEL E A RELAÇÃO COM MATERIAIS ALTERNATIVOS NA DISCIPLINA DE GEOMETRIA MOLECULAR
}

MALENA GOMES MARTINS

Instituto Federal de Educação Ciência e Tecnologia do Ceará (IFCE) - Campus Fortaleza

E-mail: malenamartins19@hotmail.com

\section{GERALDO FERNANDO GONÇALVES DE FREITAS}

Instituto Federal de Educação Ciência e Tecnologia do Ceará (IFCE) - Campus Fortaleza

E-mail: gfgfreitas@uol.com.br

\section{Pedro Hermano Menezes de Vasconcelos}

Instituto Federal de Educação Ciência e Tecnologia do Ceará (IFCE) - Campus Fortaleza

E-mail: pedrohermano@ifce.com.br

\section{RESUMO}

Este trabalho baseia-se na construção de modelos pedagógicos para o ensino de Química a partir de materiais alternativos. O conteúdo de Química que será abordado será Geometria molecular, que envolve a disposição dos átomos e suas ligações no espaço tridimensional formando figuras geométricas e ângulos específicos para cada ligação. Foi escolhido com base nas observações em sala de aula da dificuldade sentida pelos alunos em conseguir visualizar as moléculas e suas ligações no espaço. Os modelos moleculares são confeccionados a partir de material alternativo que facilita a aquisição e com preço acessível comparado aos modelos comercializados no mercado, além de possibilitar que o aluno construa seu próprio conhecimento através da representação real das moléculas apresentadas durante as aulas.

\section{PALAVRAS-CHAVE:}

Ensino; Química; Geometria molecular; Materiais Alternativos.

\section{ABSTRACT}

This work is based on the construction of pedagogical models for the teaching of Chemistry from alternative materials. The content of Chemistry that will be addressed will be molecular geometry, which involves the arrangement of atoms and their connections in three-dimensional space forming geometric figures and angles specific to each link. It was chosen based on classroom observations of the difficulty felt by students in achieving visualize the molecules and their connections in the space. The molecular models are made from alternative material that facilitates the acquisition and with affordable price compared to the models commercialized in the market, besides enabling the student to construct its own knowledge through the real representation of the molecules presented during class. 
KEYWORDS:

Teaching; Chemistry; Molecular Geometry; Alternative Materials.

\section{INTRODUÇÃO}

Um dos grandes problemas para o aprendizado de Química consiste na dificuldade, por parte dos estudantes, em compreender os níveis de representação, que podem ser concreto, verbal, simbólico, visual e gestual, onde na Química os modos concretos, visuais e verbais são os mais utilizados durante as aulas (FARIAS et al. 2014, p.851).

Diversas escolas não possuem Laboratório de Ciências nem de Informática, o que pode ser um empecilho, já outras até possuem laboratórios, mas estes não são equipados como deveriam, há falta de reagentes/vidrarias adequadas, no caso do Laboratório de Ciências. No Laboratório de Informática faltam computadores para todos os alunos e por vezes a velocidade da internet disponibilizada não permite a utilização de diversos computadores ao mesmo tempo (ALMEIDA, A. L. LOPES, N. I. 2013).

Outro problema se refere à falta de internet de qualidade em algumas cidades do interior, visto que muitos softwares necessitam de internet para funcionarem (ALMEIDA, A. L. LOPES, N. I. 2013) além de alguns softwares precisarem de licença para funcionar e o preço dessa licença pode não ser acessível aos alunos. Assim a utilização dos modelos obtidos através de materiais de baixo custo ganha ainda mais importância.

Outro método comum de se demonstrar o arranjo das moléculas no espaço é o uso de software educativos onde o aluno pode construir seus modelos por meio do computador e observar como fica a molécula em 3D (RAUPP, D. et al. 2010).

Outra dificuldade encontrada são os modelos concretos utilizados para exemplificar o ensino das moléculas sejam elas na Geometria molecular ou na disciplina de Química Orgânica. 
Onde modelos ou kits moleculares são equipamentos caros, de difícil acesso tanto para o professor quanto para o aluno, algumas vezes são disponíveis apenas em outros países onde a compra só pode ser realizada por meio da internet.

Se faz importante que os alunos possam produzir seu próprio material pedagógico para otimizar a visualização das moléculas em três dimensões, visto que a grande maioria dos estudantes possuem extrema dificuldade com abstração.

O custo-benefício desse trabalho é uma ótima opção também para as escolas que não possuem recurso financeiro para a compra de modelos pedagógicos, já que todos os materiais utilizados serão recicláveis e de fácil aquisição além de bastante acessível a todos, comparando-se com modelos moleculares disponível no mercado (FARIAS et al. 2014).

Por exemplo em sites de busca e venda o "kit molecular" com 77 (setenta e sete) peças disponíveis têm como preço $\mathrm{R} \$ 390,00$ (trezentos e noventa) com frete não incluso - dados do site de compras 3B Scientific - já o modelo molecular proposto neste trabalho apresenta 60 (sessenta) peças pelo custo de $R \$ 12,00$. Pesquisa realizada em 12 de Maio de 2016.

Os modelos criados neste trabalho não ficam restritos apenas ao uso nas aulas de Geometria molecular, os alunos podem fazê-lo em casa, já que todos os materiais são de fácil acesso, podendo assim também serem aplicados em conteúdos como modelos atômicos na disciplina de Química Geral, isomeria orgânica e também na representação de moléculas orgânicas na disciplina de Química Orgânica. Assim, este artigo tem por objetivo facilitar uma visualização facilitada das estruturas moleculares por meio da utilização de modelos moleculares, por meio da utilização de materiais de baixo custo para confeccionar os modelos moleculares, de modo a permitir sua popularização e com isso promover a aprendizagem significativa a partir da construção 
dos modelos pedagógicos com materiais alternativos para auxiliar na visualização de moléculas 3D.

\section{REVISÃO BIBLIOGRÁFICA}

A Teoria da Aprendizagem Significativa (TAS) conhecida por teoria da assimilação, proposta por David Paul Ausubel, em 1962, é uma teoria cognitivista a qual procura explicar os mecanismos internos que ocorrem na mente humana com relação ao aprendizado e à estruturação do conhecimento (AUSUBEL, 1963).

A TAS quebra o conceito que o estudante é um ser pronto para apenas receber informações, ela mostra que o aluno chega a escola com uma bagagem de conhecimentos relacionados a sua vivência e que isso influência no processo de ensino-aprendizagem (PELIZZARI et al.; 2002).

Quando o aluno se depara com novas informações ele pode decidir apreender esse conteúdo de maneira mecânica, pois ele só conseguirá simplesmente reproduzir esse conteúdo de maneira idêntica àquela que Ihe foi apresentada ou de uma forma mais significativa, onde o aluno lembrará do que foi aprendido mesmo com o passar dos anos (FRANCISCO, C. A. QUEIROZ, S. L. 2007).

Esse tipo de aprendizagem ocorre quando existem os subsunçores na estrutura cognitiva, pois eles servem de ancoragem para uma nova idéia ou aprendizagem significativa (NOVAK; GOWIN, 1984 apud AUSUBEL, 1963).

A partir desses subsunçores muitos trabalhos são reportados na literatura sugerindo o uso de estratégias de ensino que estejam relacionadas com a Teoria da Aprendizagem Significativa de David Ausubel (EBENEZER, 1992 apud NOVAK, 1984).

Em relação a esta nova aprendizagem, o conhecimento pode ser, por exemplo, um símbolo já significativo, um conceito, uma proposição, um modelo mental, uma imagem, na qual Ausubel chamava de subsunçor ou ideia-âncora (MOREIRA, 2012). 
Chama-se de subsunçor um conhecimento específico do indivíduo, que permite dar significado a novas coisas que the é apresentado ou descoberto. Seja por recepção ou descobrimento do aluno, a atribuição de significados dependerá da existência de conhecimentos prévios e a relevância que é apresentada entre eles durante o nevo aprendizado (MOREIRA, 2012).

É importante lembrar que a aprendizagem significativa define-se entre a relação dos conhecimentos prévios e novos conhecimentos, onde os novos conhecimentos podem ter significados quase tão grandes quanto aqueles conhecimentos que o aluno já traz de sua vida, seja ela no cotidiano escolar ou até mesmo em casa.

Por exemplo durante uma aula de Geometria Molecular o aluno associará o nome Geometria as formas geométricas vistas na disciplina de Matemática, isso revela que o aluno possui subsunçores que o fazem lembrar de formas geométricas, outro ponto é que o educando vê diariamente vários objetos com formas diferentes em seu cotidiano isso pode ser usado durante as aulas para fazer com que os alunos relacionem as geometrias apresentadas com seus conhecimentos prévios.

Se durante as aulas de Geometria em Matemática a aprendizagem do aluno tiver sido realmente significativa, por mais que este passe anos sem ver tal conteúdo ele fica meio que adormecido em seu subconsciente, mas a medida que vai estudando e fazendo novas assimilações esse conhecimento despertando assim uma assimilação obliteradora.

A assimilação obliteradora é uma continuidade natural da aprendizagem significativa, porém não é um esquecimento total. É uma perda de discriminabilidade, de diferenciação de significados, não uma perda de significados. Se o esquecimento for total, como se o indivíduo nunca tivesse aprendido um certo conteúdo é provável que aprendizagem tenha sido mecânica, não significativa (MOREIRA, 2012).

Portanto subsunçores são conhecimentos estabelecidos na estrutura cognitiva do sujeito que podem dar outros significados aos conhecimentos vistos em sala de 
aula, que o aluno pode possuí-lo como um conceito, uma representação, modelo etc. permitindo assim uma aprendizagem significativa e evitando o famoso "decoreba".

Moreira (2012) cita ainda que estrutura cognitiva é um conjunto hierárquico de subsunçores dinamicamente inter-relacionados. Portanto se houver uma aprendizagem super ordenada novos subsunçores podem se ligar aos já existentes, isso significa que as hierarquias de subsunçores não são fixas dentro de um mesmo campo de conhecimentos podendo variar de um campo para outro.

Logo essas hieraquias de subsunçores aplicam-se no estudo de Geometria Molecular, já que se o aluno teve uma aprendizagem realmente significativa de Formas Geométricas na Matemática, ele poderá inter-relacionar com a Geometria Molecular na disciplina de Química.

Para Ausubel (1963) o conhecimento prévio é a variável isolada mais importante para que o aluno tenha uma aprendizagem significativa de novos conhecimentos. Ou seja se fosse para isolar uma única variável como a maior influenciadora novos conhecimentos adquiridos os conhecimentos prévios do aluno seriam esta variável.

Mas caso o aluno não apresente conhecimentos prévio o que fazer? Bem os conhecimentos prévios como mostrados anteriormente podem não ser apenas conceitos ou modelos que o aluno aprendeu durante a vida escolar, pode também ser adquiridos durante a vida, desde que o ser humano nasce ele aprende diversas coisas e isso pode ser relacionado ao conteúdo estudado. Por exemplo, desde criança conseguimos diferenciar formas geométricas como círculos, pirâmides, retângulos e esses conhecimentos também são válidos no ensino de Geometria molecular.

Segundo Gowin (1984) existem algumas estratégias que são facilitadoras da Aprendizagem Significativa.

Vê epistemológico, Vê heurístico ou Vê de Gowin. É uma estratégia facilitadora da aprendizagem significativa, mais para a questão da construção do conhecimento humano, enfatizando o pensar e o fazer. Segundo Gowin, 
a medida que o aluno compreende o processo de produção do conhecimento, sua aprendizagem será significativa (MOREIRA, 1990).

Para que a Aprendizagem Significativa ocorra são essenciais duas condições, a primeira o material de aprendizagem deve ser potencialmente significativo, ou seja deve ser de linguagem clara e de fácil manuseio caso o professor esteja utilizando algum material palpável, e segundo o aprendiz deve apresentar uma predisposição para aprender, se o aluno não estiver disposto a aprender mesmo os melhores materiais serão insignificantes e estariam tendo apenas uma aprendizagem mecânica (MOREIRA, 2012).

Segundo Ausubel (1963), os principais conceitos que envolvem a TAS, são:

- Estrutura cognitiva: conjunto total de ideias que o indivíduo tem sobre uma determinada área do conhecimento, é nesta estrutura que ocorrem os processos de organização e integração de novos conhecimentos (MOREIRA, M. A. MASINI, E. A. F. S. 2006).

-Aprendizagem: deve ser um processo envolvente que prioriza a construção, modificação, enriquecimento e diversificação de esquemas do conhecimento já internalizados, a partir do significado e do sentido que pode atribuir a esses conteúdos e ao próprio fato de aprender (ROCHA, 2007).

-Aprendizagem significativa (AS): relaciona-se com a construção de significados como parte central do processo de ensino-aprendizagem. 0 estudante aprende um conteúdo quando consegue atribuir-Ihe significados. Se não há atribuição de significados, a aprendizagem é memorística, limitando-se a uma repetição do conteúdo (COLL, C. 2002).

Quando o aluno não vê sentido no que está sendo estudado ou o conteúdo é muito abstrato, normalmente ele o caracteriza como irrelevante, e consequentemente decora o conteúdo apenas para uma prova, esquecendo logo depois o que foi 
estudado, sendo esta conhecida como aprendizagem mecânica ou o famoso "decoreba".

A aprendizagem mecânica é aquela aprendizagem com pouca ou nenhuma interação com conceitos relevantes existente na estrutura cognitiva, mas de uma forma arbitrária sem relacionamento com os subsunçores específicos (AUSUBEL, 1968).

Para compreender o processo do conhecimento químico necessita-se entender três tipos de representação: macroscópico (observação dos fenômenos), microscópico (arranjo e movimento de moléculas, átomos ou partículas subatômicas) e simbólico (expressa por símbolos, números, fórmulas, etc.) (JOHNSTONE, A. H.;1993).

Porém as compreensões microscópicas e simbólicas são as mais difíceis para os estudantes porque são invisíveis e abstratas, talvez porque o pensamento dos estudantes é construído sobre a informação oral e escrita. (DAMASCENO, H. C. BRITO, M. S. WARTHA, E. J. 2008).

Quando novas informações adquirem relevância de conhecimentos numa mesma área da estrutura cognitiva o indivíduo passa a sentir necessidade de abandonar a aprendizagem mecânica por uma aprendizagem significativa surgem então os subsunçores, mas de uma forma pouco elaborados, ao passo que a aprendizagem evolui, ele tornam-se mais elaborados e com capacidade de armazenar novas informações (MOREIRA; MASINI, 2006).

Portanto as aprendizagens significativa e mecânica ocorrem mutuamente, não sendo possível, separá-las.

Moreira (2012), cita as formas e os tipos de aprendizagem significativa, quais sejam: 
- representacional: quando símbolos arbitrários passam a representar, determinados objetos ou eventos em uma relação unívoca;

- conceitual: o sujeito percebe regularidades em eventos ou objetos, passa a representá-los por determinado símbolo e não mais depende de um referente

- concreto. Trata-se, então, de uma aprendizagem representacional de alto nível. Existem duas formas de AS conceituais: formação de conceitos (ocorre na infância) e assimilação de conceitos (que ocorrem no período escolar);

- proposicional: implica dar significado a novas ideias expressas na forma de uma proposição.

Existem vários fatores que influenciam em uma aprendizagem significativa na disciplina de Química como por exemplo, alterações no processo de desenvolvimento do aprendizado da leitura, escrita e raciocínio lógico-matemático (CASTAÑO, 2003).

Ou como cita Nutti (2002) os alunos podem apresentar problemas de ordem pedagógica e/ou socioculturais.

Um ponto importante a ser destacado é a metodologia utilizada pelo professor em sala de aula, por vezes isso pode ser apontado como um dos fatores mais importantes, influenciando diretamente no processo de ensino- aprendizagem, onde pode promover interações entre os conhecimentos já existentes e os que ainda estão por vir (DUARTE et al., 2010).

Para superar essas dificuldades, tem-se sugerido uma variedade de estratégias educacionais. Incluindo o uso de modelos físicos (HUDDLE, P. A. WHITE, M. D. ROGERS, F. 2000). 
O processo de ensino-aprendizagem torna-se como uma responsabilidade tanto do professor quanto do estudante, e a relação do aluno com o coletivo e o social leva à modificação da estrutura cognitiva (NOVAK, J. D.; GOWIN, D. B. 1996).

Logo a AS é uma ótima teoria para se trabalhar no ensino de Geometria Molecular, já que pode-se utilizar os conhecimentos prévios dos alunos em relação as formas geométricas que podem ser observadas em seu cotidiano, como por exemplo a geometria em forma de gangorra que lembra bastante a gangorra de parques infantis. Observe as imagens a seguir.

Figura 01: Geometria molecular em forma de Gangorra. Fonte: http://www.oocities.org/vienna/choir/9201/geometria_molecular.htmn acesso em out. 2016.
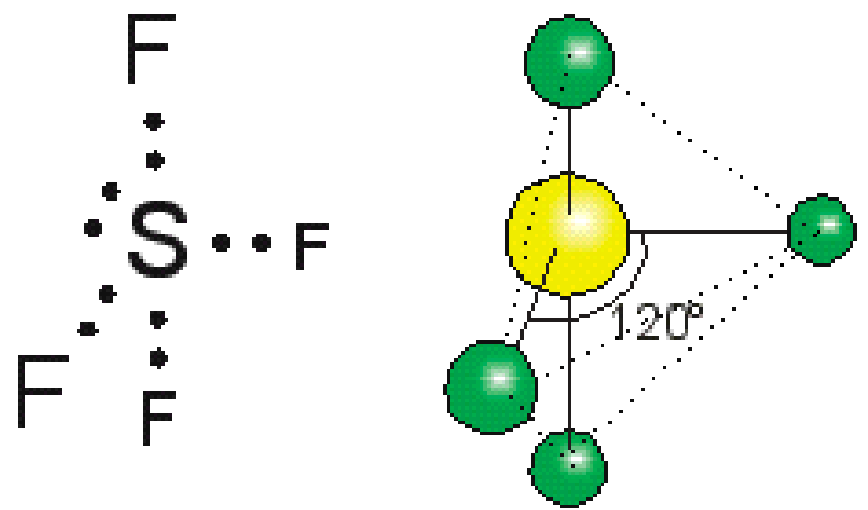

$\mathrm{SF}_{4}$ - gangorra

A partir dessa geometria denominada de gangorra o aluno pode fazer, portanto uma assimilação da molécula com o brinquedo, tornando assim a visualização da molécula um pouco menos abstrata.

Figura 02: Gangorra de Parques Infantis. Fonte: http://www.ventes.com.tr/kat-dis-mekanoyun-gruplari-151 acesso em out. 2016. 


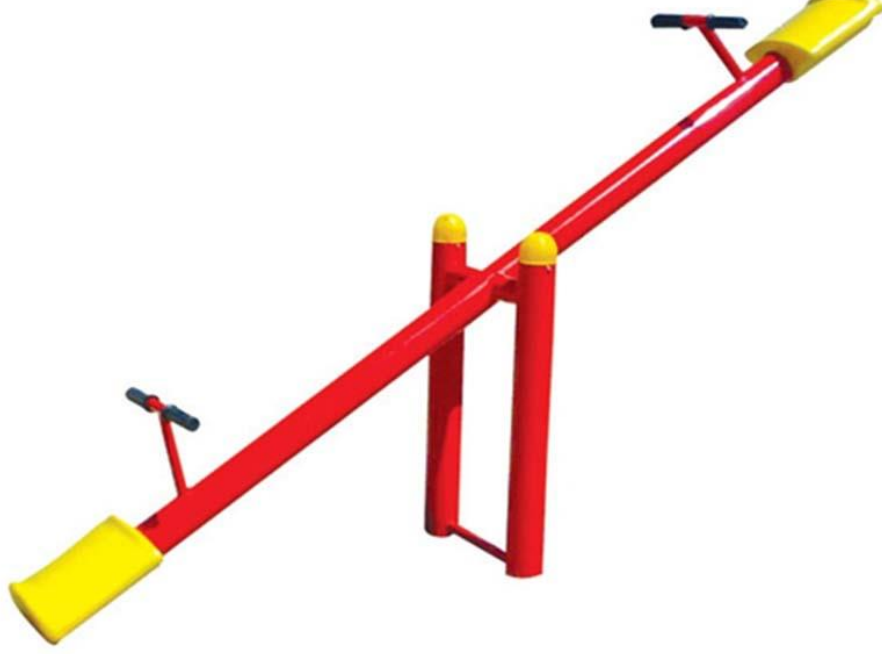

A utilização de materiais alternativos para a confecção de modelos moleculares para geometria molecular é uma forma de aproximar o aluno do meio social em que vivemos, fazendo com que ele perceba que pode construir seu próprio conhecimento com aquilo que está ao seu alcance, com baixo custo e muita eficiência (ACÁCIO, R. S. et al.; 2014).

\section{MetOdOLOGIA}

A pesquisa foi realizada no Instituto Federal de Educação Ciência e Tecnologia do Ceará - Campus Fortaleza localizado na Avenida 13 (treze) de Maio no Bairro Benfica número 2081, com o intuito de comparar a eficiência do modelo molecular proposto, confeccionado a partir de materiais alternativos visando uma aprendizagem significativa no conteúdo de Geometria Molecular na disciplina de Química.

As turmas a qual as aulas foram aplicadas no IFCE pertencem ao Curso Técnico em Gestão Ambiental e ao Curso de Tecnologia e Processos Químicos, em ambas as turmas as aulas pertencem a disciplina de Química Geral I do primeiro semestre, que tem como Docente o Professor Dr. Geraldo Freitas orientador deste trabalho, participaram das aulas um total de 30 (trinta) alunos, 8 (oito) alunos na turma do Curso Técnico em Gestão Ambiental e 22 (vinte e dois) alunos na turma do Curso de Tecnologia e Processos Químicos, as aulas foram ministradas no mesmo dia, mas em 
horários diferentes para cada turma. A metodologia utilizada na pesquisa foi a Pesquisa-ação.

Após observações em sala de aula foi possível listar as principais dificuldades dos alunos no conteúdo de Geometria Molecular que podem ser desde a visualização das moléculas em 3D, definição do átomo central, definir os ângulos de ligações e se a molécula terá ou não elétrons livres influenciando assim na sua geometria molecular.

Nessa pesquisa o planejamento de atividades dar-se da seguinte forma, são ministradas duas aulas, a primeira uma aula sem a utilização dos modelos moleculares confeccionado com materiais alternativos, apenas uma aula no "estilo tradicional" sobre o conteúdo de Geometria Molecular, e uma segunda aula onde os alunos aprendem a construir seu próprio modelo molecular com materiais de baixo custo como, por exemplo, palitos de dente, bolinhas de isopor e alfinetes etc. Ao final da aula foi aplicado um questionário para que pudesse analisar as principais dificuldades dos alunos durante a aula.

Antes da segunda aula foi preparado os modelos que seriam utilizados na confecção das moléculas, foi comprado bolinhas de isopor de dois tamanhos diferentes as maiores $(100 \mathrm{~mm})$ foram usadas para serem o átomo central e as menores $(75 \mathrm{~mm})$ os átomos ligantes, foram utilizados também palitos de dente representando as ligações entre os átomos e alfinetes que representavam os elétrons livres.

Na semana seguinte foi ministrada uma segunda aula, agora utilizando os modelos moleculares confeccionados com materiais alternativos (palitos de dente, bolinhas de isopor e alfinetes), nessa aula foi usado recursos de mídia Power point e data-show.

Além dos alunos aprenderem a construir seus próprios modelos moleculares utilizando os materiais citados anteriormente com ajuda do professor. Ao fim da 
segunda aula foi aplicado também um segundo questionário onde os alunos informavam as melhorias em relação a primeira aula ministrada, podendo validar ou não o modelo molecular proposto.

Ainda nesse segundo questionário o aluno avalia sua aprendizagem classificando-a em significativa ou não e revelando as dificuldades que ainda sentem em relação ao conteúdo de Geometria Molecular e também as dificuldades sentidas na utilização dos modelos moleculares construídos com materiais alternativos.

Os dados obtidos nessa pesquisa foram catalogados em gráficos e encontram-se no capítulo seguinte onde foram feitas as análises dos resultados obtidos.

\section{RESULTADOS E DISCUSSÕES}

Ao fim da primeira aula sobre Geometria Molecular foi aplicado um questionário, onde as perguntas baseavam-se em descobrir as principais dificuldades dos alunos em relação ao conteúdo e se eles gostariam de introduzir metodologias diferentes no estudo de Geometria Molecular.

Para saber qual a maior dificuldade que os alunos sentiram no conteúdo de Geometria Molecular, foram propostas cinco opções de possíveis dificuldades sendo a quinta opção "outros" onde havia um espaço pro aluno escrever que outro tipo de dificuldade ele havia sentido durante a aula.

As respostas descritas pelos alunos podem ser vistas no Gráfico 01 a seguir:

Gráfico 01: Dificuldade dos Alunos no Conteúdo de Geometria Molecular. 


\section{Qual sua maior dificuldade no conteúdo de Geometria Molecular?}

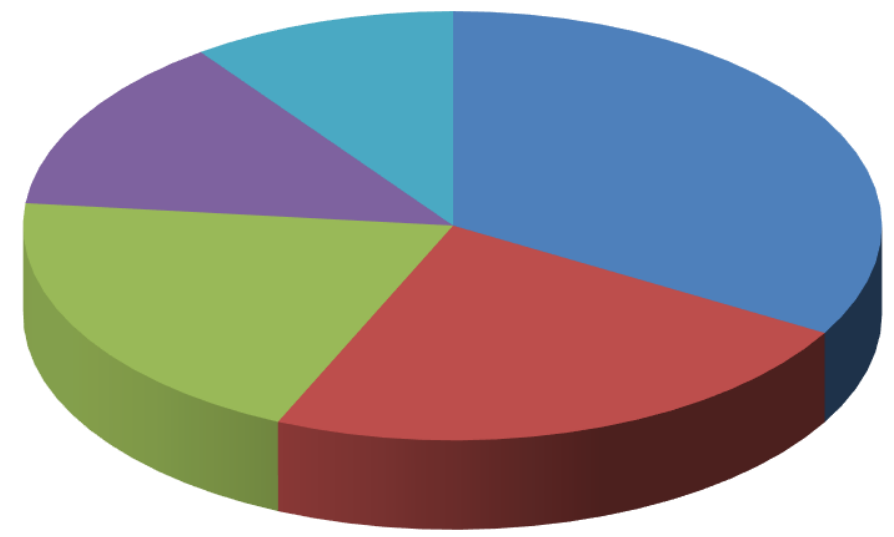

- Visualização 33,3\%

- Definir o átomo central 23,3\%

- Ângulos de ligação 20\%

Elétrons livres 13,3\%

Outros $10 \%$

Como pode ser visto no gráfico 01 os alunos ficaram bastante divididos em três principais alternativas, mas a maioria 33,3\% afirmaram sentir mais dificuldade em visualizar as moléculas e suas formas geométricas no espaço tridimensional, em seguida 23,3\% marcaram a opção "Definir o átomo central" onde citam que não conseguem diferenciar quais átomos serão ligantes e qual será o átomo central, dificuldade essa que pode estar relacionada a outro conteúdo que antecede Geometria Molecular, que consiste em realizar distribuição eletrônica e determinar a camada de valência dos átomos, vendo, portanto quantas ligações o átomo deve fazer para tornar-se o mais estável possível atingindo a estabilidade dos Gases Nobres que são oito eletros em sua última camada. Houve ainda $20 \%$ que afirmaram sentir mais dificuldade em definir os ângulos de ligação de cada molécula, dificuldade essa que pode provir da Matemática vista ainda no Ensino Fundamental e 13,3\% afirmam sentir maiores dificuldades em saber quantos elétrons livres a molécula terá, esse é um fator importante, pois a partir da repulsão eletrônica dos pares de eletros a geometria da molécula pode mudar. Apenas $10 \%$ de 30 (trinta) alunos marcaram a opção outros, 
mas não descreveram quais dificuldades foram sentidas, portanto não há como classificá-las aqui.

Segundo Baptista (2013) a dificuldade de visualização tridimensional dos alunos sempre foi citada pelos professores como um dos principais problemas no aprendizado de Química e provavelmente essa dificuldade esteja atrelado a limitação do uso de recurso por parte do professor, seja por questões metodológicas ou por disponibilidade, as moléculas sempre são mostradas aos alunos apenas com uso de quadro e pincel.

Essa pode ser a causa da maioria dos alunos terem assinalado essa opção já que essa primeira aula foi ministrada apenas com uso de quadro e pincel e as moléculas foram mostradas apenas dessa forma.

A partir dos resultados dessa questão percebe-se que o tipo de aprendizagem que os alunos mais sentem dificuldade é segundo Ausubel a aprendizagem representacional onde o aluno compreende um conceito através das representações, o que não está acontecendo, pois a principal dificuldade é na visualização das moléculas que estão sendo representadas nos livros.

A pergunta seguinte era para saber que tipo de metodologia os alunos gostariam que fosse utilizada numa aula de Geometria Molecular onde na concepção deles facilitaria a aprendizagem do conteúdo, as respostas dessa pergunta podem ser vistas a seguir no Gráfico 02:

Gráfico 02: Metodologia que os Alunos Gostariam que o Professor Utilizasse numa Aula de Geometria Molecular. 


\section{Uma maneira de melhorar a visualização de moléculas em três dimensões seria:}

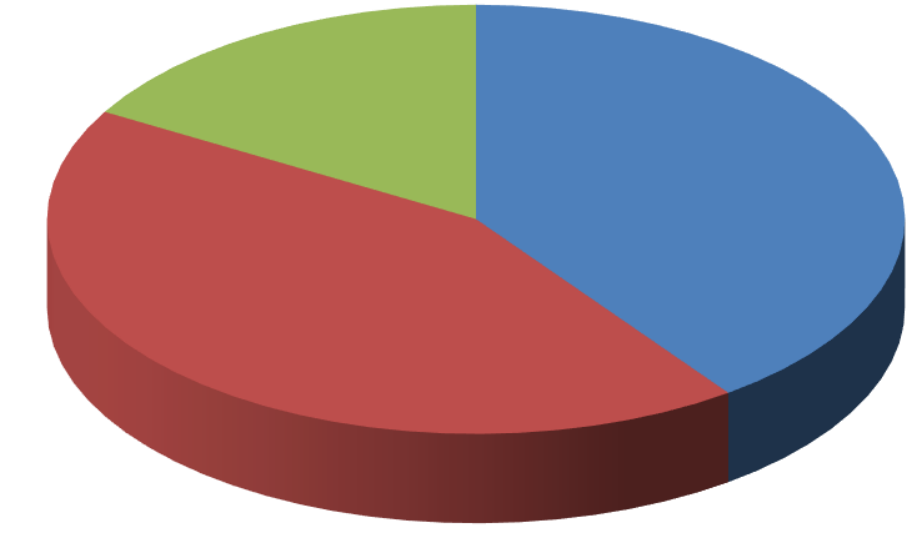

- Modelos Pedagógicos construídos com materiais alternativos $40 \%$

- Utilização de Softwares 43,3\%

Desenhos $16,6 \%$

Ao questionados sobre que tipos de metodologia os alunos gostariam que o professor utilizasse nas aulas de Geometria Molecular os alunos poderiam marcar uma de três opções oferecidas $16,6 \%$ dos alunos disseram que preferiam que o conteúdo fosse ministrado usando desenhos que representassem as geometrias das moléculas, lembrando que a aula foi ministrada utilizando desenhos representacionais das moléculas e suas respectivas geometrias com o auxílio de quadro e pincel e mesmo assim os alunos relataram como no Gráfico 01 que sentiram dificuldades no conteúdo ministrado e segundo o Gráfico 02 a maioria dos alunos classificaram a dificuldade sentida em não conseguir visualizar as moléculas e suas geometrias em três dimensões.

Utilização de Softwares foi a alternativa mais escolhida entre os alunos com 43,3\% (quarenta e três vírgula três por cento) de 30 (trinta) afirmaram que gostariam que as aulas fossem ministradas utilizando softwares que os auxiliassem a visualizar a geometria das moléculas em três dimensões e $40 \%$ indicaram que se as aulas fossem ministradas utilizando modelos pedagógicos construídos a partir de materiais 
alternativos seria mais fácil compreender as geometrias das moléculas e sua disposição no espaço 3D.

Como a utilização de software pode ficar restrita a algumas escolas devido ao número de computadores não serem suficientes para todos os alunos, softwares muitas vezes possuem licenças pagas e que a escola pública não disponibiliza de recursos para obtê-las e quando é encontrado softwares livres eles precisam da utilização da internet para funcionar, o que em escolas públicas e principalmente do interior não possuem-na com qualidade suficiente.

A Organização das Nações Unidas para Educação, Ciência e Cultura (UNESCO) em uma publicação realizada no ano de 2008 sobre o Computador na Escola revela diversas dificuldades encontradas pelos alunos na utilização dos laboratórios de informática durante as aulas, que podem ser desde a falta de computadores ou aquelas escolas que receberam computadores, mas não possuem internet, o que dificulta caso o professor queira utilizá-lo como uma ferramenta didática durante suas aulas.

Por isso o trabalho foi realizado com a construção de material pedagógico onde os alunos aprendem a construir com materiais alternativos auxiliando assim numa melhor compreensão do conteúdo de Geometria Molecular.

Essa construção de materiais pedagógicos engloba a proposta de atividade sugerida por Ausubel que é a aprendizagem concreta, onde faz-se uso de modelos concretos para facilitar a aprendizagem do aluno.

Em outra questão o aluno era indagado a marcar a alternativa que representava o valor no qual ele estava disposto a gastar na construção de um modelo molecular, as respostas podem ser conferidas no Gráfico 03 a seguir:

Gráfico 03: Preço que o Aluno Estaria Disposto a Pagar em um Modelo Molecular. 


\section{Quanto está disposto a pagar por um modelo molecular com até 70 peças?}

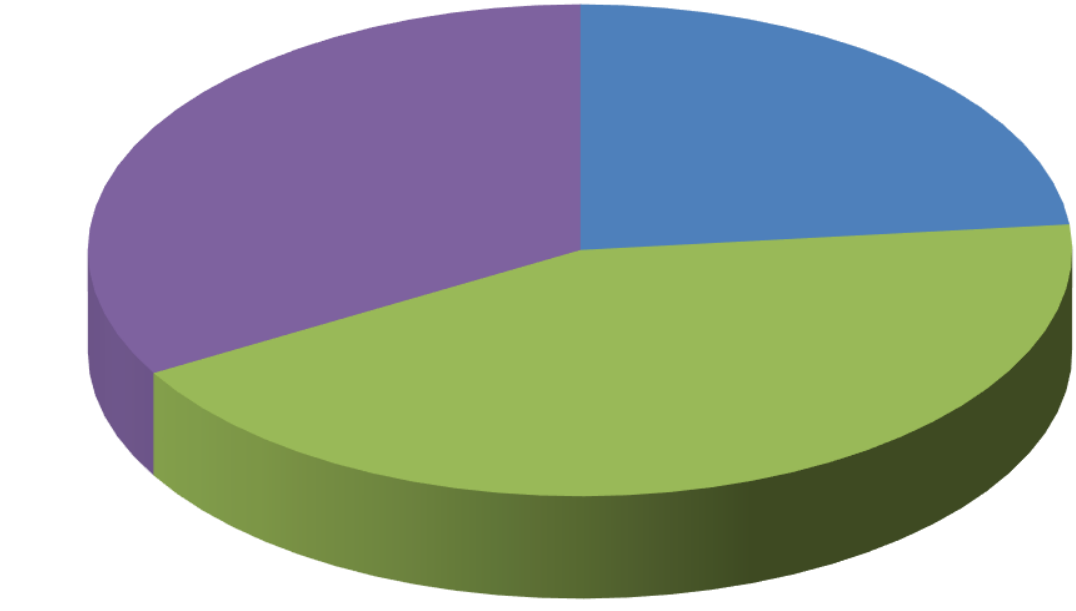

$\mathrm{R} \$ 12,00 \quad 23,3 \%$

- $\mathrm{R} \$ 390,000 \%$

- $\mathrm{R} \$ 20,0043,3 \%$

- $\mathrm{R} \$ 0,0033,3 \%$

Como pode ser observado no gráfico acima nenhum dos alunos assinalou a opção "R\$390,00" essa opção corresponde ao valor do "kit molecular" disponível no site 3B Scientific. Em seguida observa-se que a grande maioria, 43,3\% prefere gastar até $\mathrm{R} \$ 20,00$ para construir seu próprio modelo pedagógico, e que 23,3\% preferem gastar até $R \$ 12,00$ na construção do modelo molecular, visto que esse valor $(R \$ 12,00)$ foi o valor gasto para a obtenção de 77 (setenta e sete) peças do modelo molecular construído com materiais alternativos.

Houve ainda 33,3\% que assinalaram a opção onde não gostariam de gastar nada na construção de seus próprios modelos, alguns desses alunos podem ser os que marcaram as opções "Utilização de softwares" ou "Desenhos" na pergunta referente ao Gráfico 03.

Os professores de química podem construir seus próprios modelos para serem usados em suas aulas, isso é uma grande vantagem, pois podem adaptá-los da forma que quiserem em relação ao números de peças necessárias, o contrário dos modelos 
comerciais que vem com peças limitadas e não possuem um custo acessível (MORAIS, C. M. V. 2007).

Uma semana depois foi ministrada outra aula sobre o mesmo conteúdo Geometria Molecular, mas com uma metodologia diferente, onde as moléculas eram mostradas em slides e os alunos aprenderam a construir seus próprios modelos pedagógicos utilizando palitos de dentes, bolinhas de isopor e alfinetes.

Ao final da segunda aula foi aplicado um questionário com o intuito de avaliar a aprendizagem dos alunos e validar o modelo proposto.

A pergunta desse segundo questionário era para descobrir se a utilização dos modelos moleculares construídos a partir de materiais alternativos ajudou na compreensão do conteúdo de Geometria Molecular como pode ser observado no Gráfico 04:

Gráfico 04: Modelo Pedagógico Ajudou na Compreensão do Conteúdo. 


\section{0 modelo pedagógico ajudou na compreensão do conteúdo?}

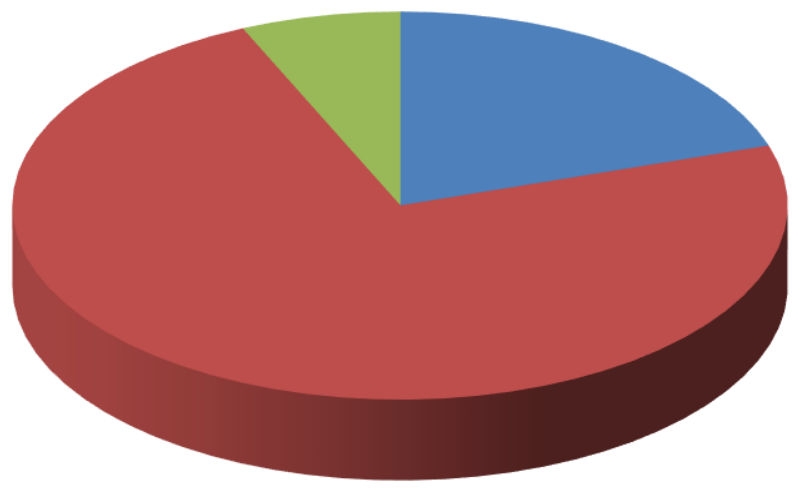

Ajudou muito $20 \%$

- Ajudou 73,3\%

Ajudou pouco 6,6\%

- Não ajudou $0 \%$

Ao serem questionados se o modelo pedagógico que aprenderam a construir durante a aula de Geometria Molecular ajudou na compreensão do conteúdo apenas 6,6\% disseram que ajudou pouco na compreensão do conteúdo em relação a aula anterior, 73,3\% afirmaram que sim o modelo ajudou numa melhor compreensão do que foi estudado e $20 \%$ afirmaram ter ajudado muito, nenhum dos alunos assinalaram a opção "Não ajudou".

Somando aqueles alunos que marcaram "Ajudou muito" e "Ajudou" pode-se concluir que a maioria dos alunos sentiu uma melhora após aprenderem a construir o próprio modelo pedagógico, auxiliando assim numa boa compreensão de Geometria Molecular, portanto a utilização dessa metodologia diferenciada pode ter proporcionado uma aprendizagem significativa do conteúdo.

Para que o aluno possa ter uma aprendizagem significativa é preciso buscar novos métodos ou alternativas de ensino com recursos que possibilitem aos alunos criarem seus próprios conceitos e aprender de forma dinâmica (Filho et. al. 2011).

As respostas dos alunos nessa pergunta torna visível que é possível obter uma melhor compreensão do conteúdo utilizando a construção de modelos moleculares 
para facilitar a aprendizagem dos alunos, mostrando assim que a aprendizagem significativa pode ser obtida fazendo uso de representações que aproximem o conteúdo ministrado, no caso Geometria Molecular do cotidiano do aluno.

Foi perguntado aos alunos se eles acharam importante terem aprendido a construir seu próprio modelo molecular e se isso os auxiliou no seu processo de Aprendizagem, as respostas podem ser vistas no Gráfico 05 a seguir:

Gráfico 05: Construção do Modelo Molecular auxiliou na Aprendizagem.

\section{Aprender a construir seu próprio modelo molecular auxiliou no seu processo de aprendizagem?}

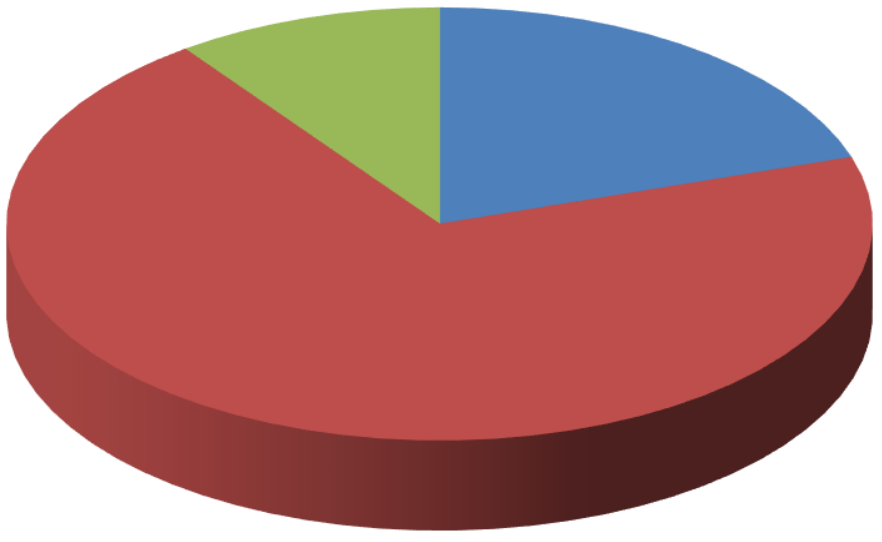

Auxiliou muito $20 \%$

Auxiliou 70\%

Auxiliou pouco $10 \%$

- Não auxiliou $0 \%$

Como pode ser visto no gráfico acima $70 \%$ dos alunos disseram que auxiliou muito em sua aprendizagem aprender a construir seu próprio modelo molecular, 20\% disseram que construir o modelo molecular com materiais alternativos auxiliou muito e apenas $10 \%$ afirmaram ter sentido pouco auxílio no processo de ensino aprendizagem com a construção do seu próprio modelo molecular, não houveram alunos que marcaram a opção em que diz que não sentiu nenhum auxílio com a produção do modelo molecular e a relação com sua aprendizagem. 
Sendo, portanto 90\% de 30 (trinta) alunos sentiram que aprender a construir seu próprio modelo pedagógico a partir de materiais alternativos auxilia de alguma forma em seu processo de ensino aprendizagem.

No mercado existem diversos kits de modelos comerciais disponíveis para compra, porém tem custo elevado, uma alternativa para alunos e professores é a construção destes com materiais de baixo custo, como insumos para artesanato e materiais recicláveis (COSTA, F. G. M. et. al. 2016).

Portanto pode-se observar nas respostas dos alunos que a utilização da aprendizagem com o uso de representações e de construção de modelos concretos facilitam a compreensão e melhoram o entendimento do conteúdo de Geometria Molecular dos alunos, comprovando assim a teoria de Ausubel.

\section{CONCLUSÕES}

Os resultados analisados indicam que os alunos sentem dificuldade em Geometria Molecular e que boa parte dessa dificuldade é atrelada ao fato da dificuldade sentida em visualizar as moléculas em três dimensões que são mostradas nos livros.

Para que essa dificuldade seja amenizada os alunos acham importante a utilização de novas metodologias de ensino que facilitem a melhor visualização dessas moléculas, para isso eles classificam como opções o uso de softwares ou modelos moleculares.

Portanto, foi escolhida a utilização dos modelos moleculares por permitir uma maior liberdade ao aluno de construir seu próprio conhecimento sem nenhum empecilho como o caso de falta de computadores na escola, internet de baixa qualidade ou licença para aquisição do software caso ele não fosse livre. 
Os alunos classificaram $\mathrm{R} \$ 20,00$ (Vinte Reais) como uma faixa de preço adequada no qual estariam dispostos a pagar por um modelo molecular que pudesse ser utilizado durante as aulas de Geometria Molecular, o que é bom visto que o valor gasto na confecção dos materiais utilizados neste trabalho foi apenas $R \$ 12,00$ (Doze Reais) contendo 77 (setenta e sete) peças.

Os resultados obtidos indicam ainda que o aluno aprender a construir seu próprio modelo molecular auxilia na aprendizagem do aluno, onde assim ele estaria construindo seu próprio instrumento de estudo e conhecimento, visto que a utilização dele não se restringe apenas ao uso no conteúdo de Geometria Molecular, mas também em outras áreas da Química.

Portanto pode-se dizer com base nos dados que os alunos obtiveram uma aprendizagem significativa do conteúdo de Geometria Molecular, devido a uma metodologia que permite que o aluno construa seu próprio conhecimento, aproximando-o assim da sua realidade e permitindo uma melhor compreensão do que Ihe é ensinado.

Cabe então aos educadores procurarem formas de tornar o ensino atraente e despertar o interesse dos alunos por essa disciplina que encanta e fascina. 


\section{REFERÊNCIAS}

ACÁCIO, R.S.; SILVA, C.B.; OLIVEIRA, E.L.S.; SILVA, K.B.; SANTOS, A.F. Geometria Molecular: Dinamizando o Ensino de Química Através da Construção de Modelos Moleculares.

<http://www.abq.org.br/simpequi/2014/trabalhos/90/3929-17982.html>. Acesso em out. 2016.

ALMEIDA, A. L. LOPES, N. I. Informática nas Escolas. 2013. Disponível em: $<$ http://catolicadeanapolis.edu.br/revmagistro/wp-content/uploads/2013/05/3INFORM\%C3\%81TICA-NAS-ESCOLAS.pdf>. Acesso em 17 de jun. 2016.

AUSUBEL, D. P. The psychology of meaningful verbal learning. New York: Grune \& Stratton, 1963.

AUSUBEL, D.P. Educational psychology: a cognitive view. New York, Holt, Rinehart and Winston, 1968.

BAPTISTA, $M$. M. Desenvolvimento e Utilização de Animações em 3D no Ensino de Química. UNICAMP. Campinas- SP 2013. Disponível em: <http://biq.iqm.unicamp.br/arquivos/770596/br-c1.html>. Acesso em jan. 2017.

CASTAÑO, J. Bases neurobiológicas del lenguaje y sus alteraciones. Revista Neurol. Buenos Aires: Argentina, 36 (8): 781-785, 2003.

COLL, C. Aprendizagem escolar e construção do conhecimento. 2a impressão. Porto Alegre: Editora Artmed, 2002.

COSTA, F. G. M..; SILVA, L. C.; COLARES, R. P.; FONSECA, A. M. Modelos Moleculares Físicos e Virtuais no Ensino de Química. UNILAB 2016. Disponível em: $<$ http://webcache.googleusercontent.com/search?q=cache:waNEw30JIsAJ:semanaun iversitaria.unilab.edu.br/gerenciar/download.php\%3Farquivo\%3D../submissao/trabal hos/d225eaebde18d871c03d7dd14045d502.pdf\%26novoNome\%3D887_MODELOS_ MOLECULARES_FISICOS_E_VIRTUAIS_NO_ENSINO_DE_QUIMICA+\&cd $=1 \& \mathrm{hl}=\mathrm{pt}-$ $B R \& c t=c|n k \& g|=b r>$. Acesso em fev. 2017.

DAMASCENO, H. C., BRITO, M. S., WARTHA, E. J. As representações mentais e a simbologia Química. In: XIV Encontro Nacional de Ensino de Química, 2008, Curitiba. Anais do XIV ENEQ. Curitiba: ENEQ, 2008. Disponível em: <http://www.quimica.ufpr.br/eduquim/eneq2008/resumos/R0623-1.pdf>. Acesso em: 05 dez. 2015.

DUARTE, R. S. A.; FREITAS, M. Z. S.; OlIVEIRA, M. R. M.; SOUSA, A. A. O Ensino de Química: as dificuldades de aprendizagem dos estudantes da rede estadual do município de Maracanaú-Ce. In: SIMPÓSIO BRASILEIRO DE EDUCAÇÃO QUÍMICA, 10, 29-31 jul. 2010. Natal, RN. Anais eletrônicos... Disponível em: 
<http://www.abq.org.br/simpequi/2010/trabalhos/102-7700.html>. Acesso em: 04 dez. 2015.

EBENEZER, J.V. (1992). Making chemistry learning more meaningful. Journal of Chemical Education, 69(6), 464-467, 1992.

FARIAS; VECCHIO; CALDAS; MATOS. Construção de um Modelo Molecular: Uma Abordagem Interdisciplinar Química-Matemática no Ensino Médio. 2014. Disponível em: <http://rvq.sbq.org.br/index.php/rvq/article/download/888/498>. Acesso em jan. 2016.

FRANCISCO, C. A. QUEIROZ, S. L. Aprendizagem Significativa e Ensino de Química: uma Análise a partir de Eventos da Área de Educação em Química no Brasil. 2007. Disponível em: <http://www.nutes.ufrj.br/abrapec/vienpec/CR2/p86.pdf>. Acesso em fev. 2017. HUDDLE, P. A. WHITE, M. D. ROGERS, F. Using Teacher Model to Correct know Misconception in Electrochemistry. Jounal of Chemical Education, no 77, p. $104-110$. 2000.

JOHNSTONE, A.H. The Development of chemistry teaching: A changing response to changing demand. Journal of Chemical Education, $n^{\circ}$ 70, p. 701-704, 1993.

MORAIS, C. M. V. Recurso Multimédia "Moleculito": Exemplo de construção e avaliação no Ensino Básico. Universidade do Porto. 2007. Disponível em: <http://www.fc.up.pt/fcup/contactos/teses/t_050370176.pdf>. Acesso em fev.2017.

MOREIRA, M. A.; MASINI, E. A. F. S. Aprendizagem significativa: A teoria de David Ausubel. 2a ed. São Paulo, Centauro, 2006.

MOREIRA, M. A. O que é a final aprendizagem significativa? Qurriculum, La Laguna, v. 25, p. 29-56, 2012.

NOVAK, J.D.; GOWIN, D.B. Aprender a ap render. Lisboa. Plátano Edições Técnicas. Tradução ao português, de Carla Valadares, do original Learning how to learn. 212p. 1996.

NOVAK, J.D. Application of advances in learning theory and philosophy of science to the improvement of chemistry teaching. Journal of Chemical Education, 61(7), 607-612, 1984.

NOVAK, J.D. \& GOWIN, D.B. Learning how to learn. Cambridge: Cambridge University Press., 1984.

NUTTI, J.Z. Distúrbios, transtornos, dificuldades e problemas de aprendizagem: algumas definições e teorias explicativas. São Carlos, SP, 2002.

PELIZZARI, A.; KRIEGL, M. L.; BARON, M. P.; FINCK, N. T. L.; DOROCINSKI, S. I.; Teoria da aprendizagem significativa segundo Ausubel. Revista PEC, Curitiba, v.2, no1, p.37-42, jul. 2001-jul. 2002. 
RAUPP, D. SERRANO, A. MARTINS, T. L. C. SOUZA, B. C. Uso de Um Software de Construção de Modelos Moleculares no Ensino de Isomeria Geométrica: Um Estudo de Caso Baseado na Teoria de Mediação Cognitiva. Revista Electrónica de Enseñanza de las Ciencias. Vol. 9 № 1 18-34. 2010. Disponível em: <http://reec.uvigo.es/volumenes/volumen9/ART2_VOL9_N1.pdf>. Acesso em 16 de mai. 2016.

ROCHA, F. E. L. Avaliação da aprendizagem: uma abordagem qualitativa baseada em mapas conceituais, ontologias e algoritmos genéticos. 2007. 181 f. Tese (Doutorado) Programa de Pós-Graduação em Engenharia Elétrica, Centro Tecnológico, Universidade Federal do Pará, Belém, PA, 2007.

UNESCO. Computador nas Escolas: Uma Dura Realidade das Escolas. 2008. Disponível em: <http://unesdoc.unesco.org/images/0015/001585/158527por.pdf>. Acesso em fev.2017. 